\title{
What Are the Conditional Survival and Functional Outcomes After Surgical Treatment of 115 Patients With Sacral Chordoma?
}

\author{
Tao Ji MD, Wei Guo MD, PhD, Rongli Yang MD, Xiaodong Tang MD, \\ Yifei Wang MD, Lin Huang MD
}

Published online: 14 March 2016

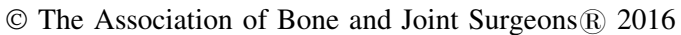

\begin{abstract}
Background Conditional survival is a measure of prognosis for patients who have already survived for a specific period of time; however, data on conditional survival after sacrectomy in patients with sacral chordoma are lacking. In addition, because sacral tumors are rare and heterogeneous, classifying them in a way that allows physicians to predict functional outcomes after sacrectomy remains a challenge. Questions/purposes (1) What is the overall survival and disease-free survival in patients treated by sacrectomy for chordoma? (2) What is the conditional survival probability and how do prognostic factors change over time in patients undergoing surgical resection for sacral chordoma? (3) What is the local recurrence rate after surgery, how was it treated, and what factors impact on local recurrence? (4) What is the postoperative motor, sensory, bowel, and bladder function by level of resection as determined by using a newly designed scoring method?
\end{abstract}

One of the authors (TJ) has received research support funding from the National Natural Science Foundation of China (No. 81402382). One of the authors (WG) received funding from the NHFPC Special Fund for Health Scientific Research in the Public Welfare (201402016).

All ICMJE Conflict of Interest Forms for authors and Clinical Orthopaedics and Related Research ${ }^{\mathbb{R}}$ editors and board members are on file with the publication and can be viewed on request. Each author certifies that his or her institution approved the human protocol for this investigation, that all investigations were conducted in conformity with ethical principles of research, and that informed consent for participation in the study was obtained.

T. Ji, W. Guo ( $₫)$, R. Yang, X. Tang, Y. Wang, L. Huang

Musculoskeletal Tumor Center, People's Hospital, Peking

University, Beijing, China

e-mail: bonetumor@163.com
Methods Between 2003 and 2012, our center treated 122 patients surgically for sacral chordoma. Of those, two died and five were lost before a minimum followup of 1 year was achieved, leaving 115 patients available for analysis in this retrospective study at a mean of 4.9 years (range, 1.310.8 years). Basically, single posterior or combined approaches were chosen based on the most cephalad extent of the tumor and resection level was normally at half or one sacral vertebrae above the tumor. The 5 -year conditional survival rate was calculated based on Kaplan-Meier survival analysis. The effect of prognostic factors on conditional survival was also explored. A newly designed score method was proposed and adopted in the current study to critically evaluate the functional outcome after resection of the sacrum. Inter- and intraobserver reliability was tested by a preliminary study using kappa statistics and Spearman rank correlation coefficients. Significant interobserver $(\mathrm{p}<0.01)$ and intraobserver agreement $(\kappa>0.75)$ were found in nine items between each observer.

Results The estimated 5-year overall survival rate was $81 \%$ (95\% confidence interval [CI], 72\%-90\%) at diagnosis. The 5-year disease-free survival rate was 52\% (95\% CI, 43\%-63\%). The 5-year conditional overall survival decreased with each additional year in the first 4 years ( $81 \%$ at diagnosis versus $60 \%$ at the fourth year, $p<$ 0.0001 ) and increased slightly in the fifth year. Patients with adequate surgical margins displayed a higher 5-year survival than those with an inadequate margin (86\% [95\% $\mathrm{CI}, 76 \%-95 \%$ ] versus $67 \%$ [95\% CI, $48 \%-85 \%$ ], $\mathrm{p}=0.01$ ) at diagnosis. Conditional survival estimates for patients who received operations elsewhere were lower than that of newly diagnosed patients treated by us at diagnosis $(64 \%$ [95\% CI, 46\%-83\%] versus $90 \%$ [95\% CI, 82\%-99\%], p = 0.012), but with the numbers we had, we could not detect a difference in conditional survival between those treated 
elsewhere first compared with those initially treated by us at 5 years. The proposed score system for function evaluation was able to distinguish different levels of resection. The overall functional results for the preservation of bilateral S1, S2, and S3 were $40 \pm 8 \%, 60 \pm 12 \%$, and $82 \pm 11 \%$, respectively. Patients who had preservation of only one S3 nerve root had more severe incontinence $(1.99 \pm 0.79$ versus $2.60 \pm 0.63, \mathrm{p}=0.01)$ and more sensory loss $(1.88 \pm 0.82$ versus $2.31 \pm 0.59, \mathrm{p}=0.02)$ than those patients with preservation of bilateral S3 nerve roots.

Conclusions The 5-year conditional survival for sacral chordoma decreased with each additional year and began to improve after the fourth year. In addition, the effect of the surgical margin and influence of previous surgery on conditional survival were not linear over time. The level of nerve root resections corresponded with the overall function scores according to the proposed scoring method. This information and scoring system should be valuable in discussing outcomes of sacrectomy in patients with chordoma who are considering this operation and serve as the basis for further study.

Level of Evidence Level III, therapeutic study.

\section{Introduction}

Primary malignant tumors of the sacrum are rare [28, 36]. Chordoma is the most common malignant primary tumor arising from the sacrum. Approximately $50 \%$ of spinal chordomas originate in the sacrum [7, 22, 44]. Sacral chordomas tend to be large at the time of diagnosis and often require en bloc resection for long-term disease-free survival [3, 12, 25, 29, 39]. Several studies have demonstrated that a negative surgical margin is the most important predictor of the local recurrence rate and survival $[3,12,13,44]$; however, wide resection is not achieved in $35 \%$ to $75 \%$ of patients undergoing surgery for this diagnosis [42]. Surgery in this anatomic site is challenging as a result of the complexity of the pelvic anatomy, adjacent visceral and vascular structures, and frequent compromise of spinopelvic continuity $[12,17,32]$. Surgeons often face a difficult choice between maximizing the preservation of function and achieving an adequate surgical margin.

To date, few large series describing the management of sacral chordoma exist [1, 42]. Moreover, prior studies have often focused on single, static 5- or 10-year overall survival or disease-free survival determined at the time of diagnosis [26, 34, 37]. In addition, prognostic factors or risk factors have been analyzed without taking into consideration the possibility of change in prognosis with time [23, 34]. Recognizing the changing likelihood of local recurrence and survival over time, conditional survival analysis offers meaningful prognostic information for patients who are successfully treated initially. Several previously published oncology papers revealed distinct patterns of conditional survival, which can vary substantially among different tumors [6, 10, 33]; however, to the best of our knowledge, no investigations have explored the conditional survival pattern of sacral chordoma. Conditional survival provides valuable and relevant information on how the prognosis may change over time. Beyond counseling, conditional survival may also help to guide disease surveillance protocols [10].

En bloc sacrectomy typically necessitates the sacrifice of some sacral nerve roots with the patients' motor, urinary, and bowel function being compromised, substantially affecting their quality of life. It is very important that the surgeons are able to give patients accurate and realistic expectations regarding the surgical results [31]. Although the relationship between the level of sacral amputation and the expected neurological deficit has been studied [31, 41], it is hard to accurately anticipate and describe motor, urinary, and bowel function based on the published data. We therefore have proposed-and here, we begin to test-a scoring method to evaluate sacral nerve function after resection of a sacral chordoma.

We therefore asked: (1) What is the overall survival and disease-free survival in patients treated by sacrectomy for chordoma? (2) What is the conditional survival probability and how do prognostic factors change over time in patients undergoing surgical resection for sacral chordoma? (3) What is the local recurrence rate after surgery, how was it treated, and what factors impact on local recurrence? (4) What is the postoperative motor, sensory, bowel, and bladder function by level of resection as determined by using a newly designed scoring method?

\section{Patients and Methods}

This was a retrospective study. Between July 2003 and December 2012, our center treated 122 patients surgically for sacral chordoma. All the operations were done by one of our three senior surgeons (WG, RY, XT). Of those, two died and five were lost before a minimum followup of 1 year was achieved, leaving 115 patients available for analysis in the current retrospective study at a mean time of 4.9 years (range, 1.3-10.8 years). There were 78 men and 37 women with a mean age of 54 years old (range, 18-82 years old). Forty-seven (41\%) patients had received previous sacrectomy elsewhere as a result of local recurrence in 38 patients and incomplete resection in nine patients. The remaining 68 patients received primary treatment after diagnosis at our institution. The average time from the onset of symptoms to final diagnosis ranged from 3 months 
to 3 years with an average duration of 9 months. Local pain was the predominant presenting symptom. A definitive diagnosis was determined using a core needle biopsy in newly diagnosed patients. With approval from the institutional review board, retrospective data on demographics, operative data, complications, postoperative functional status, and complete followup records were collected.

The operative data included the approach, methods of intraoperative hemorrhage control, surgical margin, resection level, and preservation of the sacral nerve roots. The study variables included surgical margins, other therapeutic modalities (radiotherapy and target therapy), postoperative bladder and bowel function, time to tumor recurrence, time to metastasis, and time to death. We do not routinely use preoperative radiotherapy, and the radiotherapy was only for recurrence cases (14 recurrent tumors were radiated followed by surgical removal, another five recurrent cases were only treated by radiotherapy). However, 17 patients received radiotherapy outside our hospital and referred to us for surgical treatment. Eleven patients tried targeted medicine, imatinib (PDGFR-beta positive on immunohistochemistry). A diagnosis of chordoma was made based on histopathologic features, tumor cells lying in a myxoid background, the nuclei being round and regular with little cytologic atypia, having cytoplasmic vacuolization, by two experienced pathologists (DS, KS).

Our techniques for sacrectomy have been previously reported $[19,27,45]$. The goal of the surgery was to obtain a wide or at least a marginal surgical margin resection. Depending on the extent of the tumor, a combined anterior and posterior approach or posterior approach alone was used. The methods of intraoperative hemorrhage control were as previously described $[18,40]$. The resection was defined as an adequate margin resection when a wide or marginal margin was determined by pathology report, whereas an inadequate margin resection was used for patients with intralesional margins, including tumor spillage, or palliative resections where gross tumor was left behind [13].

The resection level was determined by the most proximal part of the tumor. Usually, half or one normal vertebra (adjacent first normal proximal intervertebral disk) was set as the margin if possible. When the tumor invades caudally to S2-S3, it was normally resected en bloc using the posterior-only approach. Briefly, dissection was performed through the subcutaneous tissue, fascia, and muscles. The presacral space was reached by severing the sacrotuberous ligament. Next, the dissection was performed bluntly on the anterior aspect of the sacrum up to the S2 level and laterally to the sacroiliac joint. The presacral space was padded with gauze. A laminectomy was then performed. The thecal sac and S1-S3 nerve were exposed. The thecal sac was severed and ligated just below the S3 nerve. The S3 nerve was preserved at least on one side. If the S2 vertebral body is involved, then the tumor can also be excised using the posterior approach. The dural sac was ligated and sutured below the S1 nerve. Bilateral S2 nerves were preserved if the nerve roots could be dissected from the tumor surface. To protect the presacral nerves and blood vessels, a bone burr was used to complete the osteotomy. There were a total of 86 patients with the tumor invading below $\mathrm{S} 2$, and 75 patients received a sacrectomy using the posterior-only approach.

For tumors invading S1 or with a more cephalad extent, en bloc total sacrectomy was performed through the onestage combined anterior and posterior approach ( 25 of 29 patients), and the one-stage posterior-only approach [45] was used in the remaining four patients. For the anterior approach, an ilioinguinal incision was made and the retroperitoneal space was exposed. For larger sacral chordomas, preoperative embolization and an intraaortic balloon were used to temporarily occlude the abdominal aorta to reduce intraoperative bleeding. After the ureters were dissected and protected, L5-S1 discectomy was then performed. Further dissection was performed to expose the greater sciatic notch and the cephalad part of the iliosacral joint. Two guide needles were then inserted through the skin immediately beneath the greater sciatic notch and above the cephalad part of the iliosacral joint, bringing the two ends of the silicone tube out of the body and leaving the tube loop anterior to the iliosacral joint. Next, a Gigli saw was placed through a silicone tube during the posterior approach for tumor resection and osteotomies were performed laterally to the tumor [45]. Pre- and immediate postoperative radiotherapy were used in five and eight patients, respectively.

Thirty-six patients (31\%) had wound complications, including wound dehiscence in 20 patients and deep infection in 16 patients. Sixteen patients with deep infection received once or staged débridement (totally 25 procedures) to close the wounds. Ten patients required a flap to close the skin defect. Sixteen patients developed postoperative cerebrospinal fluid leaks and were successfully managed by 7 - to 10-day bed rest with the head of the bed elevated approximately $15^{\circ}$ to $30^{\circ}$. Radiotherapy was not routinely given preoperatively. Of the 31 patients with a history of conventional or stereotactic radiotherapy, 11 patients developed a postoperative wound infection, which required additional soft tissue reconstruction, and three patients developed postoperative rectal fistula. Although this was not one of the study objectives, a chi square test showed there was a significant difference between the two groups. Patients who received radiotherapy had a higher risk of wound infection than those who did not $(\mathrm{p}<$ 0.0001). Seven hardware failures were found in 58 patients who received rod-screw instrumentation.

Routine followup evaluation was performed every 3 months for the first 2 years, every 6 months for the next 3 

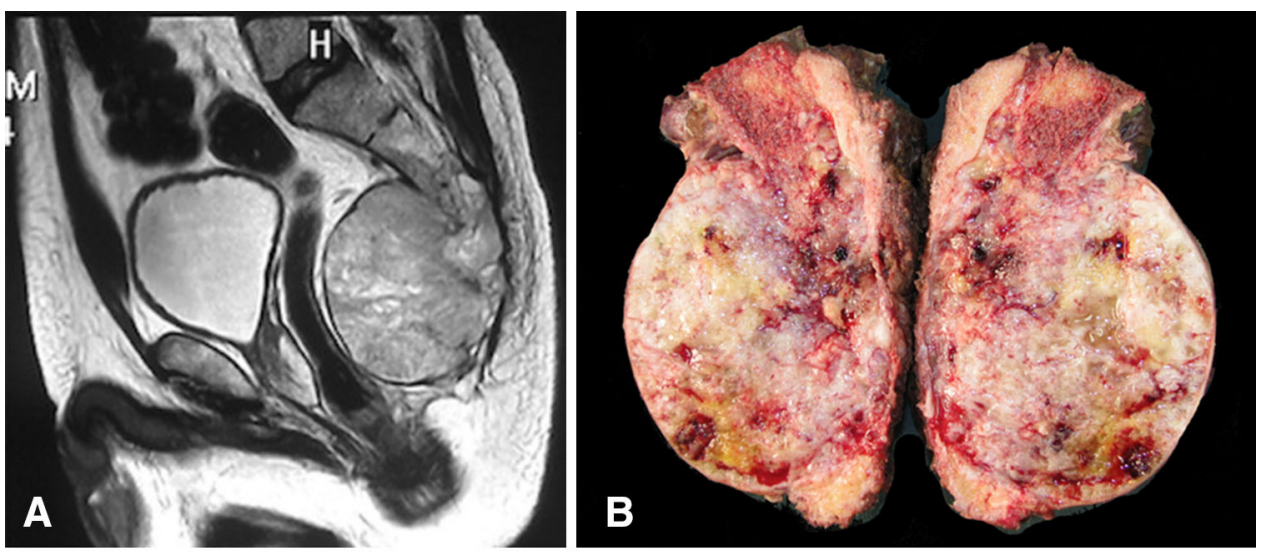

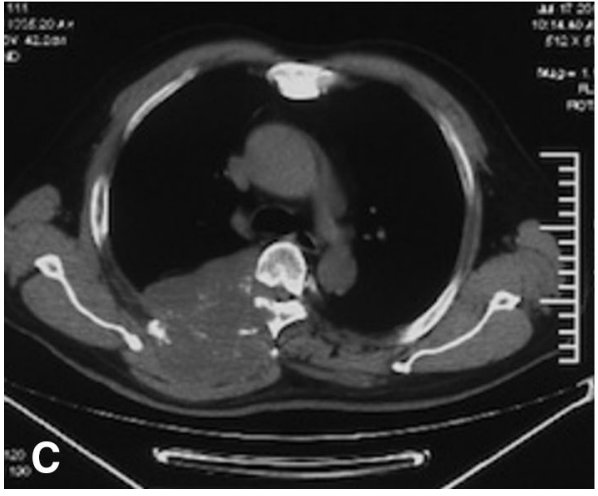

Fig. 1A-D An illustrative case of bone metastasis after sacrectomy without local recurrence is shown. The patient was a 56-year-old man with sacral chordoma. (A) Sagittal MRI showed tumor invading to S1.

years, and then annually. Each followup evaluation included a clinical examination, functional evaluation, and imaging studies with plain film, CT scan, or MRI for evaluation of local control. For metastasis surveillance, PET-CT or chest CT, bone scan, and abdominal ultrasound were routinely checked (Fig. 1).

Motor, bladder, and bowel functionalities were recorded as the assessment at the most recent followup or the last assessment before local recurrence. A newly designed scoring method was used (Table 1). Inter- and intraobserver reliability was tested by a preliminary study using kappa statistics and Spearman rank correlation coefficients. Significant interobserver $(\mathrm{p}<0.01)$ and intraobserver agreement $(\kappa>0.75)$ were found in nine items between each observer. The scoring system consisted of three main domains with three items in each domain for a more detailed evaluation of sacral nerve function. The three functional domains were (1) motor function and sensation of lower limbs; (2) urination and uriesthesia; and (3) defecation and rectal sensation. Each item was assessed on a 4-point scale $(0,1,2,3)$. A score of 3 indicates normal and 0 indicates a total loss of function with a maximum score of 27 points, which was recorded as $100 \%$.

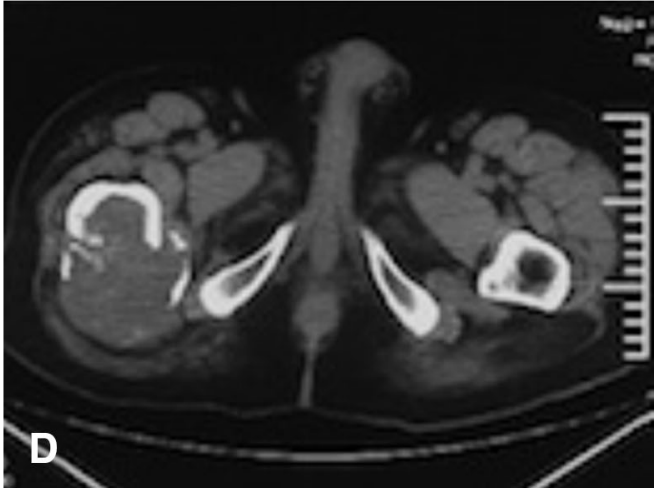

(B) The gross specimen after en bloc total sacrectomy is shown. (CD) Bone metastases were found during followup at 4.5 years after surgery without evidence of local recurrence.

Statistical Analysis

We used survival analysis using Kaplan-Meier methods to evaluate overall survival, disease-free survival, and recurrence-free survival using the SPSS software package (Version 20.0; Chicago, IL, USA). The mathematical definition of conditional survival (CS) can be expressed as the following: $\operatorname{CS}(t \mid s)$ is the probability of surviving from an additional $t$ years given that the patient has already survived for $s$ years. This conditional probability is given as $\mathrm{CS}(t \mid s)=\mathrm{S}(s+t) /(s)$. In principle, $\mathrm{CS}$ can be calculated considering the usual Kaplan-Meier estimates [21]. Thus, for instance, if $\mathrm{CS}(5 \mid 3)$ is to be determined, we simply divided the Kaplan-Meier estimator at $\mathrm{t}=8$ by the KaplanMeier estimator at $\mathrm{t}=3$. We calculated a 5 -year survival estimate at the time of diagnosis and a 5-year survival estimate conditional at 1,2, 3, 4, and 5 years of survival. When a survival curve shows a changing hazard rate over time, this will be reflected as a change in conditional survival as more time elapses from the time of diagnosis. Chisquare testing was performed to determine whether the previous surgery, most cephalad extent, adjuvant radiotherapy, surgical margin, and intraoperative hemorrhage control had an effect on local recurrence. The survival 


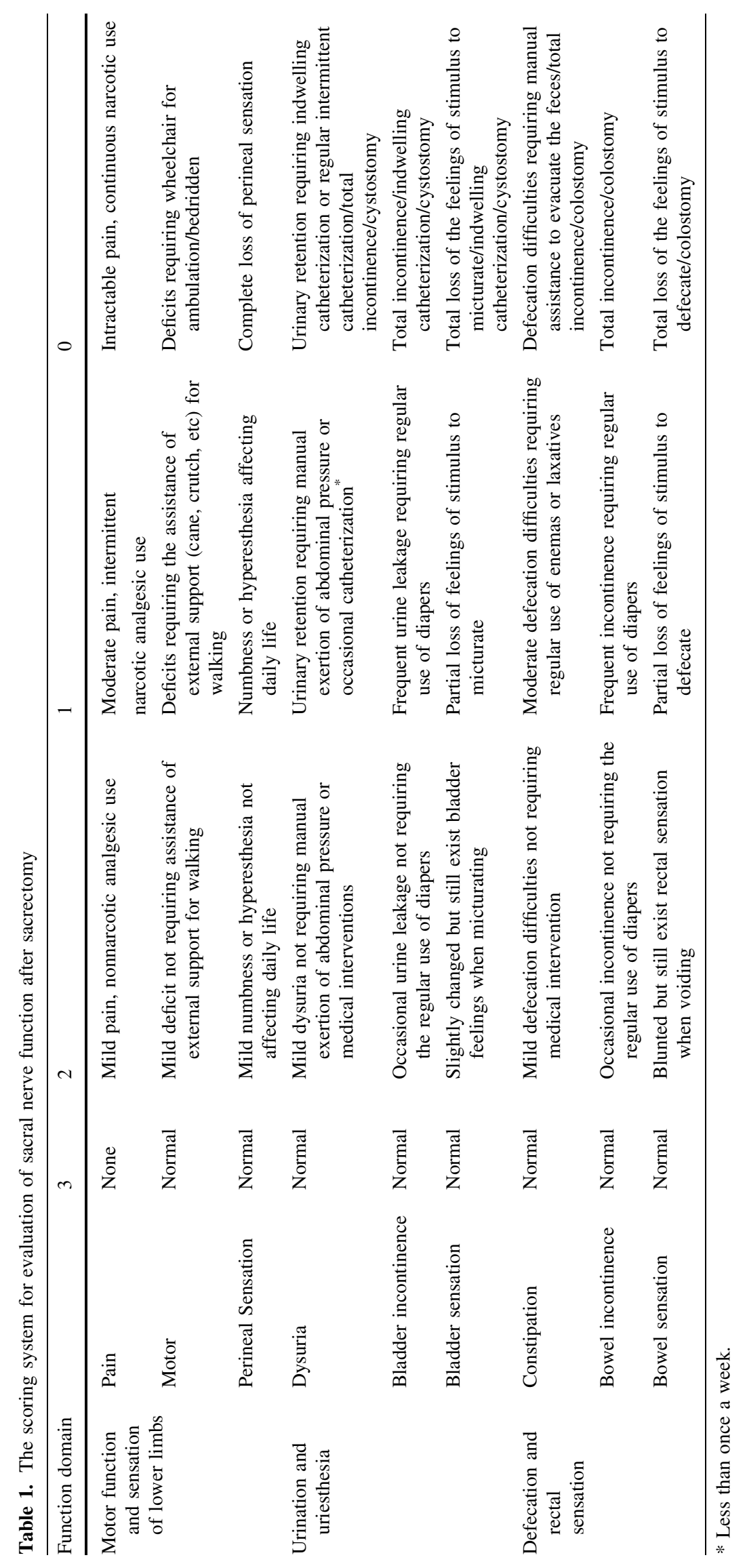


Table 2. Estimated survival rates of patients in relation to clinical factors

\begin{tabular}{|c|c|c|c|c|c|}
\hline \multirow[t]{2}{*}{ Variables } & \multicolumn{5}{|c|}{ Patient survival (with $95 \% \mathrm{CI}$ ) } \\
\hline & & 3 years $(\%)$ & 5 years $(\%)$ & 10 years $(\%)$ & $\mathrm{p}$ value* \\
\hline All patients & & $94(89-99)$ & $81(72-90)$ & $62(47-77)$ & - \\
\hline \multirow[t]{2}{*}{ Age (years) } & $<65(\mathrm{n}=81)$ & $92(86-98)$ & $84(74-94)$ & $62(43-81)$ & 0.375 \\
\hline & $\geq 65(\mathrm{n}=34)$ & $97(91-100)$ & $75(57-93)$ & $43(6-80)$ & \\
\hline \multirow[t]{2}{*}{ Gender } & Male $(\mathrm{n}=78)$ & $93(87-99)$ & $78(67-89)$ & $65(49-81)$ & 0.979 \\
\hline & Female $(\mathrm{n}=37)$ & $95(88-100)$ & $86(72-100)$ & $47(17-77)$ & \\
\hline \multirow[t]{2}{*}{ Previous surgery } & No $(n=68)^{\dagger}$ & $97(93-100)$ & $90(82-98)$ & $64(43-85)$ & 0.012 \\
\hline & Yes $(n=47)$ & $88(78-98)$ & $64(45-83)$ & $43(14-72)$ & \\
\hline \multirow[t]{2}{*}{ Most cephalad extent } & Above S3 $(n=70)$ & $94(89-99)$ & $80(71-89)$ & $58(42-74)$ & 0.790 \\
\hline & $\mathrm{S} 3$ and below $(\mathrm{n}=45)$ & $93(85-100)$ & $77(61-93)$ & $55(35-75)$ & \\
\hline \multirow[t]{2}{*}{ Surgical margin } & Adequate $(\mathrm{n}=77)^{\dagger}$ & $94(89-99)$ & $86(76-96)$ & $69(49-89)$ & 0.009 \\
\hline & Inadequate $(\mathrm{n}=38)$ & $92(84-100)$ & $67(49-85)$ & $33(8-58)$ & \\
\hline \multirow[t]{2}{*}{ Intraoperative hemorrhage control } & With $(\mathrm{n}=32)$ & $93(84-100)$ & 79 (61-97) & $58(21-95)$ & 0.849 \\
\hline & Without $(\mathrm{n}=83)$ & $96(92-100)$ & $91(84-98)$ & $48(28-68)$ & \\
\hline \multirow[t]{2}{*}{ Adjuvant radiotherapy } & With $(\mathrm{n}=31)$ & $97(91-100)$ & $81(64-98)$ & $46(20-72)$ & 0.359 \\
\hline & Without $(n=84)$ & $92(86-98)$ & $80(70-90)$ & $62(41-83)$ & \\
\hline \multirow[t]{2}{*}{ Reresection for recurrence } & Yes $(n=32)$ & $90(80-100)$ & $71(52-90)$ & $38(4-72)$ & 0.125 \\
\hline & No $(\mathrm{n}=83)$ & $95(90-100)$ & 85 (76-94) & $65(47-83)$ & \\
\hline
\end{tabular}

* Log-rank test; ${ }^{\dagger}$ the category with the better survival; $\mathrm{CI}=$ confidence interval.

difference was compared with the log-rank test. Probability values $<0.05$ were considered statistically significant.

\section{Results}

The estimated 5-year overall survivorship was 81\% $(95 \%$ confidence interval [CI], 72\%-90\%) at diagnosis. The 5year disease-free survivorship was 52\% (95\% CI, 43\%$63 \%)$. During followup, $24(21 \%)$ patients died of disease. Sixty-three $(55 \%)$ patients were alive without evidence of local or distal relapse. There were $28(24 \%)$ patients alive with disease. Twenty patients (17\%) had distant metastases, including lung metastases in 13 patients observed at a median time of 42 months, bone metastases in nine patients, liver metastasis in three patients, and soft tissue metastasis in two patients. The clinical and operation-related factors that may have an association with decreased survival were analyzed (Table 2). Two factors that had a negative effect on survival were previous surgery $(p=0.012)$ and inadequate margin $(\mathrm{p}=0.009)$.

The 5-year conditional overall survival decreased with each additional year in the first 4 years $(81 \%$ at diagnosis versus $60 \%$ at fourth year, $\mathrm{p}<0.0001$ ) with a subsequent increase in the fifth year (Fig. 2). The 5-year conditional survival for patients with an adequate surgical margin remained unchanged from Year 1 to Year $5(\mathrm{p}>0.05)$;

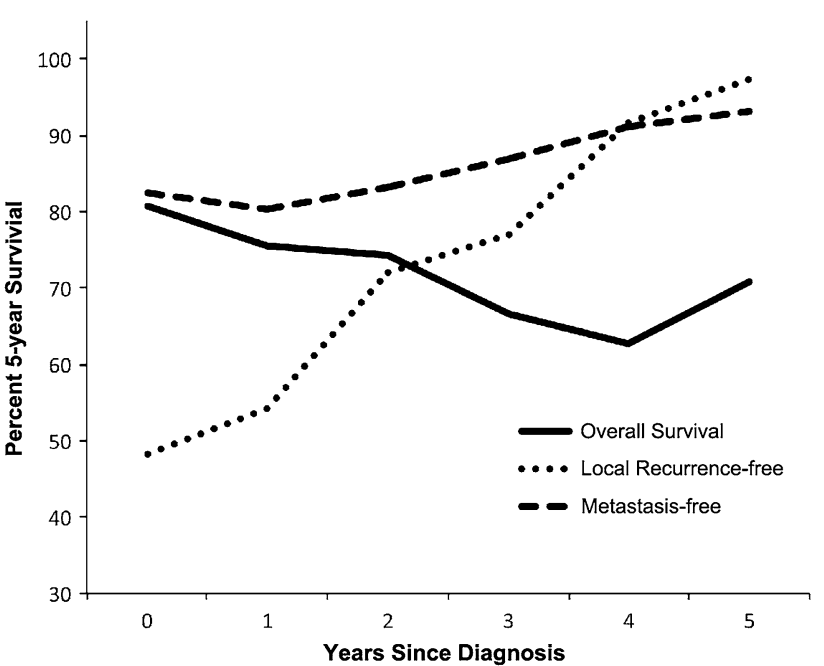

Fig. 2 The solid line shows conditional survival of patients who survived 0 to 5 years after diagnosis. The conditional recurrence-free and metastasis-free survival increased with each additional year since diagnosis.

however, in patients with inadequate surgical margin resections, conditional survival demonstrated a decrease at the third year $(67 \%$ at diagnosis versus $36 \%$ at 3 year after surgery, $p<0.0001$ ) and increased from the fourth year (Fig. 3A), which indicated that the surgical margin had the largest effect on shortening survival during the third and fourth years compared with that of baseline and afterward. 
Patients who had received operations before referral had a poorer 5-year survival at diagnosis compared with those who were newly diagnosed $(64 \%, 95 \%$ CI, 45\%-83\% versus $90 \%, 95 \% \mathrm{CI}, 82 \%-98 \%, \mathrm{p}=0.012)$, but the difference decreased with time and no longer existed 5 years after diagnosis $(67 \%$ with $95 \%$ CI, $31 \%-87 \%$ versus $71 \%$ with $95 \%$ CI, 52\%-86\%, p > 0.05) (Fig. 3B). Five-year recurrence-free conditional survival estimates improved with each additional year of survival after diagnosis. Local recurrence-free 5-year survival was $48 \%$ (95\% CI, 38\%$59 \%$ ) at diagnosis, worse than that of $97 \%$ (95\% CI, 92\%$100 \%$ ) at the fifth year $(\mathrm{p}<0.01)$. For metastasis-free survival, 5-year conditional survival at the fifth year was $89 \%(95 \% \mathrm{CI}, 83 \%-97 \%)$ and $85 \%(95 \% \mathrm{CI}, 78 \%-92 \%)$ at diagnosis $(\mathrm{p}=0.21)$ (Fig. 1).

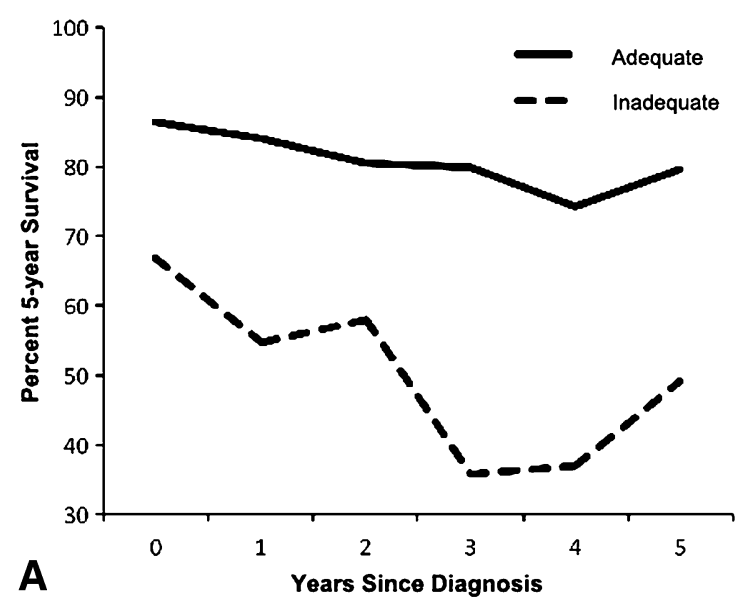

In total, there were $53(46 \%)$ local recurrences after the operations at a mean time of 42 months. The therapeutic approach most frequently used in cases of local recurrence was reresection, accounting for $60 \%$ (32 of 53) of recurrences. Palliative radiotherapy was attempted in 18 (34\%) patients. Of the 68 patients who were initially diagnosed at our center, 25 had local recurrence after surgery. Nineteen patients received reresections and five patients received radiotherapy alone. One patient was recruited in a clinical trial. Previous surgery before referral $(p=0.001)$ and inadequate surgical margin $(\mathrm{p}<0.001)$ were found to be associated with a greater risk of local recurrence by univariate analysis (Table 3 ).

The level of sacral amputation correlates with the expected neurological deficit and overall postoperative

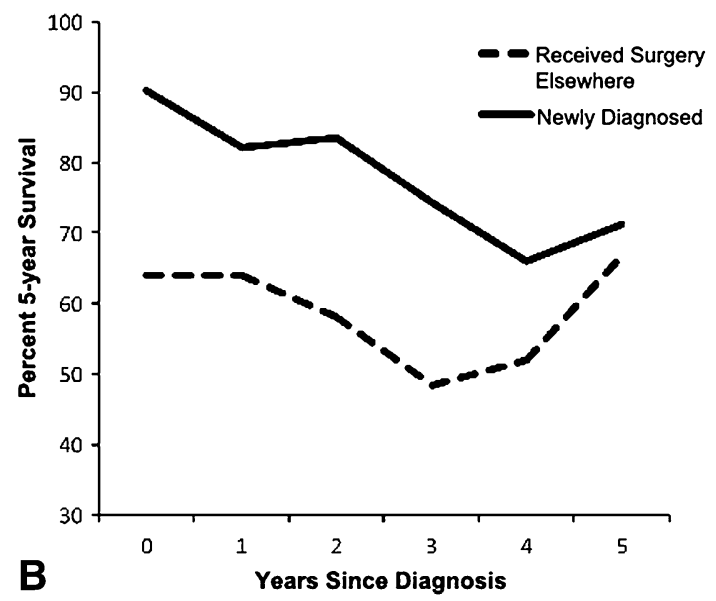

Fig. 3A-B This graph shows the effect of surgical margin (A) and previous surgery (B) on conditional survival.

Table 3. Local recurrence stratified by potential risk factors

\begin{tabular}{|c|c|c|c|c|}
\hline \multirow[b]{2}{*}{ All patients $(\mathrm{N}=115)$} & \multicolumn{4}{|l|}{ Local recurrence } \\
\hline & Variables & Recurrence $(\%)$ & No recurrence $(\%)$ & $\mathrm{p}$ value ${ }^{*}$ \\
\hline \multirow[t]{2}{*}{ Age (years) } & $<65(\mathrm{n}=81)$ & $33(41)$ & $48(59)$ & \multirow[t]{2}{*}{0.053} \\
\hline & $\geq 65(\mathrm{n}=34)$ & $20(59)$ & $14(41)$ & \\
\hline \multirow[t]{2}{*}{ Gender } & Male $(n=78)$ & $40(51)$ & $38(49)$ & \multirow[t]{2}{*}{0.061} \\
\hline & Female $(n=37)$ & $13(35)$ & $24(65)$ & \\
\hline \multirow[t]{2}{*}{ Previous surgery } & No $(n=68)^{\dagger}$ & $25(38)$ & $43(62)$ & \multirow[t]{2}{*}{0.001} \\
\hline & Yes $(n=47)$ & $28(60)$ & $19(40)$ & \\
\hline \multirow[t]{2}{*}{ Most cephalad extent } & Above S3 $(n=70)$ & $38(54)$ & $32(46)$ & \multirow[t]{2}{*}{0.038} \\
\hline & S3 and below $(\mathrm{n}=45)^{\dagger}$ & $15(33)$ & $30(67)$ & \\
\hline \multirow[t]{2}{*}{ Adjuvant radiotherapy } & With $(\mathrm{n}=31)$ & $17(55)$ & $14(45)$ & \multirow[t]{2}{*}{0.360} \\
\hline & Without $(\mathrm{n}=84)$ & $36(43)$ & $48(57)$ & \\
\hline \multirow[t]{2}{*}{ Surgical margin } & Adequate $(\mathrm{n}=77)^{\dagger}$ & $25(32)$ & $52(68)$ & \multirow[t]{2}{*}{$<0.001$} \\
\hline & Inadequate $(\mathrm{n}=38)$ & $28(74)$ & $10(26)$ & \\
\hline \multirow[t]{2}{*}{ Intraoperative hemorrhage control } & With $(\mathrm{n}=32)$ & $12(38)$ & $20(62)$ & \multirow[t]{2}{*}{0.337} \\
\hline & Without $(\mathrm{n}=83)$ & $41(49)$ & $42(51)$ & \\
\hline
\end{tabular}

* Multivariate analysis; ${ }^{\dagger}$ the category with lower risk of local recurrence, significant at $\alpha=0.05$. 
Table 4. Function scores of 91 survived patients stratified by level of spared sacral nerves*

\begin{tabular}{lllllcc}
\hline $\begin{array}{l}\text { Level of sacral } \\
\text { nerve spared }\end{array}$ & $\begin{array}{l}\text { Number } \\
\text { of cases }\end{array}$ & $\begin{array}{l}\text { Motor function and sensation } \\
\text { of lower limbs }\end{array}$ & $\begin{array}{l}\text { Urination and } \\
\text { urieshtesia }\end{array}$ & $\begin{array}{l}\text { Defecation and } \\
\text { rectal sensation }\end{array}$ & Total \\
\hline Bilateral L5 & 4 & $2.50 \pm 2.12$ & $3.50 \pm 2.12$ & $1.50 \pm 2.12$ & $7.50 \pm 6.36$ & $27.78 \pm 23.57$ \\
Bilateral S1 & 16 & $5.33 \pm 1.52$ & $3.67 \pm 0.58$ & $1.67 \pm 0.58$ & $10.67 \pm 2.08$ & $39.51 \pm 7.71$ \\
Bilateral S2 & 20 & $6.20 \pm 1.40$ & $4.90 \pm 1.37$ & $5.10 \pm 1.97$ & $16.20 \pm 3.33$ & $60.0 \pm 12.3$ \\
Unilateral S2 & 15 & $6.25 \pm 0.96$ & $4.25 \pm 0.50$ & $4.00 \pm 1.41$ & $14.50 \pm 1.73$ & $53.70 \pm 6.42$ \\
Bilateral S3 & 20 & $7.63 \pm 1.02$ & $7.06 \pm 1.69$ & $7.31 \pm 1.30$ & $22.00 \pm 2.99$ & $81.48 \pm 11.07$ \\
Unilateral S3 & 16 & $7.00 \pm 1.26$ & $6.67 \pm 2.25$ & $7.00 \pm 1.41$ & $20.67 \pm 4.80$ & $76.54 \pm 17.79$ \\
\hline
\end{tabular}

* The data are presented as the mean $\pm \mathrm{SD}$; ${ }^{\dagger}$ most cephalad level of preserved sacral nerve root. The lines between cells indicated significant difference $(\mathrm{p}<0.05)$.

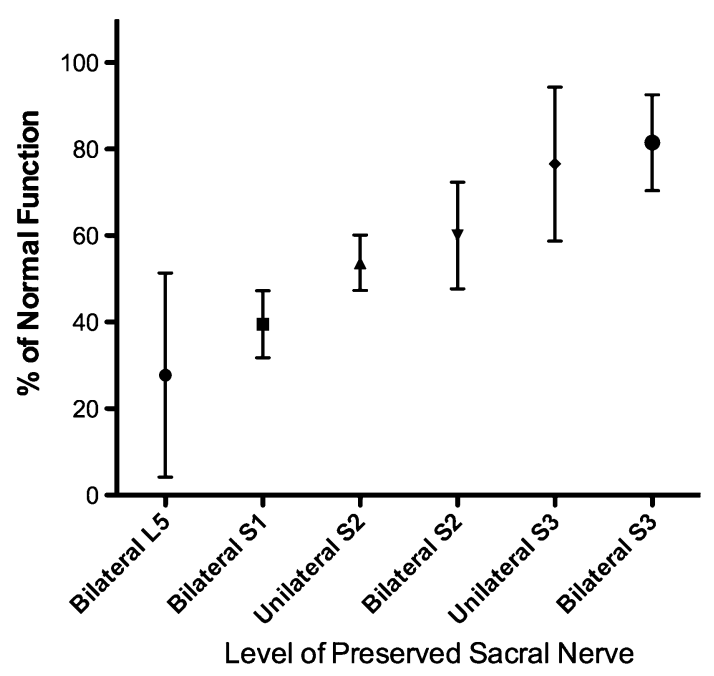

Fig. 4 Postoperative overall function, including motor, bladder, and bowel function, correlated with the level of sacral nerve preservation (mean with SD).

function (Table 4; Fig. 4). In this scoring system, a higher score is better. The average functional score based on the proposed scoring method was $67 \%$ (range, $11 \%-96 \%$ ). The difference observed in motor function and sensation of the lower limb was between bilateral S1 preserved and sacrificed $(\mathrm{p}<0.01)$. Patients with a resection of the bilateral $\mathrm{S} 1$ nerve had impaired plantar flexion of the feet but were able to walk with canes or with support. Five patients reported moderate pain and analgesics were routinely used. One patient with only bilateral L5 nerve roots preserved experienced a total loss of sensation of the planta pedis and posterior of the leg. The average score for bladder function (9 points in total) was 5 for patients with bilateral S2 preserved, which is lower than that of 7 for patients with bilateral S3 preserved $(p<0.01)$. There were six of 16 patients with unilateral S3 preserved and 13 of 20 patients with bilateral S3 preserved who achieved 9 points in urinary function domain. Patients with bilateral S3 preserved had a lower incidence of urinary leakage compared with patients with single S3 preserved with a mean bladder incontinence score of $2.8 \pm 0.54$ and $1.7 \pm 0.72$, respectively $(\mathrm{p}=0.04)$. Moreover, bilateral S3 preservation provided better bladder sensation during micturition than unilateral S3 preserved $(p=0.03)$. Constipation was the most common problem in bowel function evaluation. We did not attempt to relate this to the nine patients who were taking narcotics routinely. There were $55(60 \%)$ patients with mild constipation symptoms and nine patients with moderate constipation. However, fecal incontinence was less common, and only two patients frequently demonstrated incontinence. Preservation of bilateral S3 nerve roots decreased incontinence $(p=0.01)$ and sensation loss $(p=0.02)$ compared with when only unilateral the $S 3$ nerve root was severed.

\section{Discussion}

The primary treatment for sacral chordoma is en bloc resection with a wide surgical margin. Previous clinical series have demonstrated that a negative surgical margin is the single most important predictor of tumor recurrence and long-term survival $[13,43]$. Tumors with more proximal involvement necessitating total or subtotal sacrectomy pose the greatest management challenges as a result of the conflict between achieving a wide surgical margin and sacral nerve preservation [12, 13, 24, 43]. Data on conditional survival after sacrectomy for sacral chordoma are not well established. A clinically useful scoring system for evaluation of the functional outcome after sacrectomy should be of importance in advising patients who are about to undergo a sacrectomy. The present study showed 5-year conditional survival for sacral chordoma decreased with each additional year $(81 \%$ at diagnosis versus $60 \%$ at the fourth year) and began to increase after the fourth year.

This study had a number of limitations. First, the authors acknowledge that this study consisted of cases from one institution, which might pose a potential referral bias of the current group of patients such as a higher incidence of recurrent cases and larger size of tumor at diagnosis. 
Second, the retrospective method means that it was impossible to verify some variables had an effect on outcome as a result of a lack of a control group such as whether radiotherapy affected local recurrence. The third limitation of this study was the inability to analyze how function changes with time. The best way to assess these changes is to use dynamic analysis based on the followup results at different intervals after surgery for postoperative evaluation. A time-dependent function analysis after sacrectomy will be addressed in future studies. Also, the new scoring system used in the current study was not formally validated. The purpose of using the system here was for descriptive purpose. However, the purposed scoring method was functional and warranted further validation.

In our group, the 5-year tumor-free survival rate was $52 \%$, and the 5 -year overall survival rate was $81 \%$. The survival rate of the patients in our group was among the range reported in some studies by other groups, but we also studied conditional survival in this article. In 2003, Baratti et al. [2] reported 5-year and 10-year tumor-free survival rates of $60.6 \%$ and $24.2 \%$ and overall survival rates of $87.8 \%$ and $48.9 \%$, respectively. In 2005, Fuchs et al. [13] reported 5-year and 10-year tumor-free survival rates of $59 \%$ and $46 \%$ and overall survival rates of $74 \%$ and $52 \%$, respectively. Reresection after local recurrence achieved the same survival results, which suggested that surgical intervention should be reserved for local recurrence with the intention of long-term local control.

We found that the conditional survival of patients with sacral chordoma decreased with each additional year until the fourth year and increased slightly at the fifth year. The pattern is different from that of osteosarcoma, Ewing's sarcoma, and chondrosarcoma, of which the conditional survival improved with each year $[10,30]$. This is potentially explained by the first 3 to 4 years after surgery, representing a period of high probability of local recurrence.

Conditional survival is different from standard survival predictors, which are less able to take into consideration the changes of variables at subsequent times after initial assessment. Conditional survival has been extensively studied for numerous malignancies [5, 6, 8, 15, 33]; however, only a few studies have focused on bone sarcoma, including osteosarcoma, Ewing's sarcoma, and chondrosarcoma $[10,30]$. To the best of our knowledge, this is the first study to investigate the conditional survival of sacral chordoma.

The mean time of local recurrence in the current group was 42 months, after which the 5 -year conditional survival estimate improved. The conditional 5-year survival of patients who received an inadequate margin resection showed the lowest survival probability during the third and fourth years postoperatively, which indicated that the effect of the surgical margin on conditional 5-year survival was the greatest between 3 and 4 years after surgery. Despite a similar trend of the surgical margin and previous surgery in conditional survival over time, an inadequate margin and previous surgery before referral continued to have a lower 5 -year conditional survival, which is consistent with previous studies demonstrating that the surgical margin is an important predictor of survival $[9,23,26,34,38,42]$. The surgical margin is the main predictor factor for local control and disease-free survival [3, 11, 24, 44]. Intralesional surgery resulted in a high recurrence rate. York et al. [44] reported a $83 \%$ local recurrence rate of sacral chordoma after intralesional surgery. In the current study, all 16 patients who received primary surgery with an inadequate margin before referral developed local recurrence. Although all of the patients accepted adequate margin resection, there were still 12 patients $(75 \%)$ who developed local recurrence after a second operation, demonstrating that the first procedure with an adequate margin is very important for local control. Bergh et al. [3] reported a $37 \%$ local recurrence rate at a median of 8 years of followup. Baratti et al. [2], Hulen et al. [24], and Hanna et al. [20] reported local recurrence rates of $54 \%, 56 \%$, and $60 \%$, respectively, at mean followups of 5.9, 5.5, and 4.4 years, respectively, after wide resection. Fuchs et al. [13] reported an excellent recurrence rate of $5 \%$ in 21 patients who all received wide resection. This rate was the best local control rate in the literature. However, of 31 patients with an inadequate surgical margin, 22 cases developed local recurrence $(71 \%)$. In our series, 25 of 68 patients $(37 \%)$ who accepted primary surgery at the authors' institution developed local recurrence. Our results are consistent with previous findings published in the literature. The trend for 5-year recurrence-free and metastasis-free conditional survival is different from conditional overall survival, both of which exhibited an increase with each additional year. Interestingly, the shape of the local recurrence-free conditional survival curve of chordoma more closely approximates conditional survival in osteosarcoma, Ewing's sarcoma [30], and Grade 3 chondrosarcoma [10], reflecting similarities in the biological aggressiveness of the tumor regardless of local recurrence resulting from the specific location. Importantly, there was a minimal increase in 5-year metastasis-free survival from diagnosis to the fifth year, which might be the result of the behavior of the tumor itself rather than the surgical margin. The interval changes of recurrence-free conditional survival were larger in magnitude than that of metastasis-free conditional survival, which provided evidence that local recurrence had a larger effect on survival than the biological behavior of the tumor. The difference was not captured using conventional assessment modalities of survival.

In our study, we found that disability in the lower legs was minor if bilateral $\mathrm{S} 1$ was preserved, which is consistent 
with the anatomical targets of these nerves. Because of the sacrifice of the $\mathrm{S} 1$ nerve roots, the patient had impairment of plantar flexion power. Loss of the L5 roots or additional injury to the lumbosacral trunks caused further difficulty with footdrop, which may be counteracted using ankle-foot orthoses [35]. Preservation of the bilateral S2 roots maintained $60 \%$ of the overall function in the current group of patients, suggesting that basic bowel and bladder function was preserved. The overall functional score for sparing unilateral and bilateral S3 was $77 \%$ and $85 \%$, respectively. It has been reported that the level of resection in sacrectomy can predict neurological deficit and postoperative function [12, 31]. Gunterberg et al. [16] performed a neurological evaluation after sacrectomy in 1975. The relationship between resection levels and postoperative function was further studied and confirmed by other authors since Gunterberg et al. It has been reported that the preservation of bilateral L5 is necessary for satisfactory ambulation. Bilateral S2 is required to walk normally and for satisfactory bladder and bowel function, and bilateral preservation of S3 is necessary to maintain normal bladder and bowel function [14]. Todd et al. [41] found that sparing at least one S3 nerve preserved bowel and bladder function in most patients. In a review article by Kayani et al. [26], the preservation of the bilateral S2 nerve roots was proposed to maintain $50 \%$ of normal urinary and bowel function. For S3 nerve roots, there is no consensus on their effect on residual bowel and bladder function. However, we found that the difference between unilateral and bilateral S3 nerve root preservation lay in urinary leakage and bowel and bladder sensation, which has not been previously reported.

Finally, we introduce a new scoring system, which we hope others will find useful to critically evaluate the functional outcome after sacrectomy in a more detailed fashion. However, the system was not formally validated. A new scoring system should be evaluated for test-retest reliability, measurement error, floor/ceiling effects, and other qualities before being accommodated into practice. In the current study, kappa statistics and Spearman rank correlation coefficients were analyzed to verify there was agreement among observers. Intraobserver reliability was tested by kappa coefficient. Further study will explore key validation criteria of the system such as content validity, internal consistency, test-retest reliability, construct validity, and responsiveness through a prospective study design. To best of our knowledge, no specific and validated scoring instrument can be used in clinical practice. Biagini et al. [4] developed a functional scoring system to evaluate neurological deficits after sacral resection. However, the degree of function compromised was not accurately described and incontinence and sensation deficit were also not listed in separate items. These limitations were indicated in a later application by Moran et al. [31]. Based on Biagini et al.'s scoring system, a newly designed scoring system was proposed and adopted in the current study aimed at accurately evaluating postoperative function after sacrectomy. The preliminary results showed that the proposed score system can distinguish the functional outcome according to the resection level, which warranted its further application on functional evaluation and can be extended to both preoperative and postoperative along with other clinical spectra.

In summary, the 5-year conditional survival for sacral chordoma decreased with each additional year and started to improve after the fourth year. The effect of the surgical margin and previous surgery on conditional survival showed a different pattern. The effect of an inadequate surgical margin was most important between the third and fourth years after diagnosis. The survival disadvantage of previous surgery elsewhere decreased with time and diminished at 5 years compared with patients who were newly diagnosed in the current group. Local recurrencefree and metastasis-free conditional survival improved with each additional year. The level of nerve root resections corresponded well with the overall functional scores according to the proposed scoring method. The minor difference between unilateral and bilateral S3 nerve preservation was that preservation of bilateral S3 nerve roots decreased the incontinence and sensation loss compared with sacrificing one S3 nerve root. Although larger studies and more data will be necessary to confirm the merits of our scoring method, we believe these data will lead to further study and be of help to surgeons when advising patients about sacrectomy.

Acknowledgments We thank Sainan Zhu PhD, for her assistance on statistics. We also thank pathologists, Dr Danhua Shen and Dr Kunkun Sun, for their work on the pathologic diagnosis.

\section{References}

1. Angelini A, Pala E, Calabro T, Maraldi M, Ruggieri P. Prognostic factors in surgical resection of sacral chordoma. J Surg Oncol. 2015;112:344-351.

2. Baratti D, Gronchi A, Pennacchioli E, Lozza L, Colecchia M, Fiore M, Santinami M. Chordoma: natural history and results in 28 patients treated at a single institution. Ann Surg Oncol. 2003;10:291-296.

3. Bergh P, Kindblom LG, Gunterberg B, Remotti F, Ryd W, MeisKindblom JM. Prognostic factors in chordoma of the sacrum and mobile spine: a study of 39 patients. Cancer. 2000;88:2122-2134.

4. Biagini R, Ruggieri P, Mercuri M, Capanna R, Briccoli A, Perin S, Orsini U, Demitri S, Arlecchini S. Neurologic deficit after resection of the sacrum. Chir Organi Mov. 1997;82:357-372.

5. Bleyer A, Choi M, Fuller CD, Thomas CR Jr, Wang SJ. Relative lack of conditional survival improvement in young adults with cancer. Semin Oncol. 2009;36:460-467. 
6. Choi M, Fuller CD, Thomas CR Jr, Wang SJ. Conditional survival in ovarian cancer: results from the SEER dataset 19882001. Gynecol Oncol. 2008;109:203-209.

7. Dahlin DC, Maccarty CS. Chordoma. Cancer. 1952;5:1170-1178.

8. Davis FG, McCarthy BJ, Freels S, Kupelian V, Bondy ML. The conditional probability of survival of patients with primary malignant brain tumors: Surveillance, Epidemiology, and End Results (SEER) data. Cancer. 1999;85:485-491.

9. Dubory A, Missenard G, Lambert B, Court C. 'En bloc' resection of sacral chordomas by combined anterior and posterior surgical approach: a monocentric retrospective review about 29 cases. Eur Spine J. 2014;23:1940-1948.

10. Duchman KR, Lynch CF, Buckwalter JA, Miller BJ. Estimated cause-specific survival continues to improve over time in patients with chondrosarcoma. Clin Orthop Relat Res. 2014;472:25162525.

11. Fourney DR, Gokaslan ZL. Current management of sacral chordoma. Neurosurg Focus. 2003;15:E9.

12. Fourney DR, Rhines LD, Hentschel SJ, Skibber JM, Wolinsky JP, Weber KL, Suki D, Gallia GL, Garonzik I, Gokaslan ZL. En bloc resection of primary sacral tumors: classification of surgical approaches and outcome. J Neurosurg Spine. 2005;3:111-122.

13. Fuchs B, Dickey ID, Yaszemski MJ, Inwards CY, Sim FH. Operative management of sacral chordoma. J Bone Joint Surg Am. 2005;87:2211-2216.

14. Fujimura Y, Maruiwa H, Takahata T, Toyama Y. Neurological evaluation after radical resection of sacral neoplasms. Paraplegia. 1994;32:396-406.

15. Fuller CD, Wang SJ, Thomas CR Jr, Hoffman HT, Weber RS, Rosenthal DI. Conditional survival in head and neck squamous cell carcinoma: results from the SEER dataset 1973-1998. Cancer. 2007;109:1331-1343.

16. Gunterberg B, Norlen L, Stener B, Sundin T. Neurologic evaluation after resection of the sacrum. Invest Urol. 1975;13:183188.

17. Gunterberg B, Romanus B, Stener B. Pelvic strength after major amputation of the sacrum. An exerimental study. Acta Orthop Scand. 1976;47:635-642.

18. Guo W, Ji T, Tang X, Yang Y. Outcome of conservative surgery for giant cell tumor of the sacrum. Spine. 2009;34:1025-1031.

19. Guo W, Xu WP, Yang RL, Tang XD. [The surgical management of sacral tumors] [in Chinese]. Zhonghua Wai Ke Za Zhi. 2003;41:827-831.

20. Hanna SA, Aston WJ, Briggs TW, Cannon SR, Saifuddin A. Sacral chordoma: can local recurrence after sacrectomy be predicted? Clin Orthop Relat Res. 2008;466:2217-2223.

21. Hieke S, Kleber M, Konig C, Engelhardt M, Schumacher M. Conditional survival: a useful concept to provide information on how prognosis evolves over time. Clin Cancer Res. 2015;21:1530-1536.

22. Higinbotham NL, Phillips RF, Farr HW, Hustu HO. Chordoma. Thirty-five-year study at Memorial Hospital. Cancer. 1967;20:1841-1850.

23. Hsieh PC, Xu R, Sciubba DM, McGirt MJ, Nelson C, Witham TF, Wolinksy JP, Gokaslan ZL. Long-term clinical outcomes following en bloc resections for sacral chordomas and chondrosarcomas: a series of twenty consecutive patients. Spine. 2009;34:2233-2239.

24. Hulen CA, Temple HT, Fox WP, Sama AA, Green BA, Eismont FJ. Oncologic and functional outcome following sacrectomy for sacral chordoma. J Bone Joint Surg Am. 2006;88:1532-1539.

25. Kaiser TE, Pritchard DJ, Unni KK. Clinicopathologic study of sacrococcygeal chordoma. Cancer. 1984;53:2574-2578.

26. Kayani B, Hanna SA, Sewell MD, Saifuddin A, Molloy S, Briggs TW. A review of the surgical management of sacral chordoma. Eur J Surg Oncol. 2014;40:1412-1420.
27. Kim I, Kim DH. Surgical resection of sacral tumors/sacrectomy and lumbopelvic reconstruction. In: Kim DH, Vaccaro AR, Dickman CA, Cho D, Lee S, Kim I, eds. Surgical Anatomy and Techniques to the Spine. $2^{\text {nd }}$ ed. Philadelphia, PA, USA: WB Saunders; 2013:532-544.

28. 28. Lovett R. Sacral tumor. J Kans Med Soc. 1966;67:553-555.

29. McLoughlin GS, Sciubba DM, Suk I, Witham T, Bydon A, Gokaslan ZL, Wolinsky JP. En bloc total sacrectomy performed in a single stage through a posterior approach. Neurosurgery. 2008;63:ONS115-120; discussion ONS120.

30. Miller BJ, Lynch CF, Buckwalter JA. Conditional survival is greater than overall survival at diagnosis in patients with osteosarcoma and Ewing's sarcoma. Clin Orthop Relat Res. 2013;471:3398-3404.

31. Moran D, Zadnik PL, Taylor T, Groves ML, Yurter A, Wolinsky JP, Witham TF, Bydon A, Gokaslan ZL, Sciubba DM. Maintenance of bowel, bladder, and motor functions after sacrectomy. Spine J. 2015;15:222-229.

32. Murakami H, Kawahara N, Tomita K, Sakamoto J, Oda J. Biomechanical evaluation of reconstructed lumbosacral spine after total sacrectomy. J Orthop Sci. 2002;7:658-664.

33. Nathan H, de Jong MC, Pulitano C, Ribero D, Strub J, Mentha G, Gigot JF, Schulick RD, Choti MA, Aldrighetti L, Capussotti L, Pawlik TM. Conditional survival after surgical resection of colorectal liver metastasis: an international multi-institutional analysis of 949 patients. J Am Coll Surg. 2010;210:755-764, 764-766.

34. Osaka S, Osaka E, Kojima T, Yoshida Y, Tokuhashi Y. Longterm outcome following surgical treatment of sacral chordoma. $J$ Surg Oncol. 2014;109:184-188.

35. Rajpal S, Douglas Orr R, Steinmetz MP, Smith DA. Sacral tumors. In: Benzel EC, ed. Spine Surgery. 3rd ed. Philadelphia, PA, USA: WB Saunders; 2012:1123-1133.

36. Randall RL, Bruckner J, Lloyd C, Pohlman TH, Conrad EU 3rd. Sacral resection and reconstruction for tumors and tumor-like conditions. Orthopedics. 2005;28:307-313.

37. Rotondo RL, Folkert W, Liebsch NJ, Chen YL, Pedlow FX, Schwab JH, Rosenberg AE, Nielsen GP, Szymonifka J, Ferreira AE, Hornicek FJ, Delaney TF. High-dose proton-based radiation therapy in the management of spine chordomas: outcomes and clinicopathological prognostic factors. J Neurosurg Spine. 2015;23:788-797.

38. Ruggieri P, Angelini A, Ussia G, Montalti M, Mercuri M. Surgical margins and local control in resection of sacral chordomas. Clin Orthop Relat Res. 2010;468:2939-2947.

39. tener B, Gunterberg B. High amputation of the sacrum for extirpation of tumors. Principles and technique. Spine. 1978;3:351-366.

40. Tang X, Guo W, Yang R, Tang S, Dong S. Use of aortic balloon occlusion to decrease blood loss during sacral tumor resection. $J$ Bone Joint Surg Am. 2010;92:1747-1753.

41. Todd LT Jr, Yaszemski MJ, Currier BL, Fuchs B, Kim CW, Sim FH. Bowel and bladder function after major sacral resection. Clin Orthop Relat Res. 2002;397:36-39.

42. Varga PP, Szoverfi Z, Fisher CG, Boriani S, Gokaslan ZL, Dekutoski MB, Chou D, Quraishi NA, Reynolds JJ, Luzzati A, Williams R, Fehlings MG, Germscheid NM, Lazary A, Rhines LD. Surgical treatment of sacral chordoma: prognostic variables for local recurrence and overall survival. Eur Spine J. 2015;24:1092-1101.

43. Yonemoto T, Tatezaki S, Takenouchi T, Ishii T, Satoh T, Moriya $\mathrm{H}$. The surgical management of sacrococcygeal chordoma. Cancer. 1999;85:878-883.

44. York JE, Kaczaraj A, Abi-Said D, Fuller GN, Skibber JM, Janjan NA, Gokaslan ZL. Sacral chordoma: 40-year experience at a major cancer center. Neurosurgery. 1999;44:74-79; discussion 79-80.

45. Zang J, Guo W, Yang R, Tang X, Li D. Is total en bloc sacrectomy using a posterior-only approach feasible and safe for patients with malignant sacral tumors? J Neurosurg Spine. 2015:1-8. 